\title{
Effect of Road Vibrations on the Mechanical Properties of Olive Fruit During Transport
}

\author{
Davood Karimi ${ }^{1}$, Mahdi Rashvand ${ }^{1,}$, , Ashkan Shokrian ${ }^{2}$ \\ ${ }^{1}$ Machine design and Mechatronics Department, Institute of Mechanics, Iranian Research Organization for Science and Technology, Tehran, \\ Iran \\ ${ }^{2}$ Department of Mechanics of Agricultural Machinery, Faculty of Agricultural Engineering and Technology, University of Tehran, Karaj, Iran
}

Email address:

Mahdi.rashvand@irost.ir (M. Rashvand)

${ }^{*}$ Corresponding author

To cite this article:

Davood Karimi, Mahdi Rashvand, Ashkan Shokrian. Effect of Road Vibrations on the Mechanical Properties of Olive Fruit During

Transport. American Journal of Mechanics and Applications. Vol. 7, No. 2, 2019, pp. 30-34. doi: 10.11648/j.ajma.20190702.13

Received: May 31, 2019; Accepted: July 5, 2019; Published: July 17, 2019

\begin{abstract}
Post-harvest processes, such as transportation and packaging, should be carried out in such a way that less damage is made to the product. Inappropriate transport of fruits causes mechanical damage. Transport vibrations have a great effect on the extent of damage to agricultural products. In this research, the effects of road vibration on the mechanical properties of olive fruit, including fracture force, fracture energy and elasticity modulus were measured through pressure testing by the instrument before and after Vibration and results were checked. The effect of different parameters of vibrations caused by road transport (frequency, acceleration and time) on the mechanical properties of olive was investigated. Experiments were carried out at two levels of $7.5 \mathrm{~Hz}$ and $13 \mathrm{~Hz}$, two acceleration levels of $0.3 \mathrm{~g}$ and $0.7 \mathrm{~g}$ and two levels of 30 and 60 minutes. The results of the data analysis showed that the effects of vibration frequency, vibration acceleration, vibration duration were significant on the amount of damage during vibration at the $1 \%$ level. The factors caused reduction in mechanical properties.
\end{abstract}

Keywords: Mechanical Properties, Olive, Physical Properties, Vibration

\section{Introduction}

Olive Tree is one of the Mediterranean plants that the fruit of this tree used as a cannery [1]. Olive is common fruit among the people from past and has a key role in healthy [2]. Olive fruit is considered to be a significant source of oil. Over the past few decades, the medicinal properties of olive have been recognized more than ever [3]. Olive oil is rich in vitamins and antioxidants and helps to prevent heart attacks [4].

Mechanical damage that caused by mechanical harvesting, transportation or processing of agricultural products every year reduces the income of food production, significantly [5]. Among agriculture products, fruits have a high sensitivity to mechanical damage due to their low resistance of skin and high humidity [6]. Therefore, in order to minimize waste, there is requirement for proper post-harvest management and appropriate transportation and maintenance techniques. The amount of waste after harvesting of fruits due to mechanical damage was estimated to be about $30-40 \%$ [7]. If the transport does not appropriate, it will cause heavy movement of the fruit during transportation, and the collision with the surfaces of the vehicle, lead to deformation of the tissues [8].

Considering the availability of suitable olive cultivate in the world and the growing market demand for this product, more attention to increasing the quality and quantity of production in the world is a very important issue [9]. Usually, during transportation, there are various damage to the olive, which may reduce the stiffness, cracking of the skin and flesh of fruit.

A lot of research has been done related to mechanical damage of agriculture products such as apples [10], peaches [11], tomatoes [12], potatoes [13] and pomegranates [14]. In a study to reduce the modulus of tomato elasticity, it was concluded that during transportation, the young modulus of the fruit decreases significantly [15]. In another tomato vibration study, the maximum damage occurs when the fruit was placed above the bottom of the box [16]. In the study, the mechanical damage to pears in the rear position of the truck 
over the entire route was reported more than the forward position (Zhou et al, 2007).

In another study, the effect of vibration frequency, vibration acceleration, vibration duration and position of product inside the storage on the amount of damage to watermelon was significant at $1 \%$ level. Vibrations with frequency of $5.5 \mathrm{~Hz}$, acceleration of 0.7 and a period of 60 minutes have caused the most damage. The damage caused to the watermelons in the upper layers of the storage was higher than the watermelons located in the lower and middle layers [17]. Efforts and study in order to reduce the tensions caused by transportation, play key role for increasing the shelf-life of the product to prevent post-harvest damage. Considering the development of olive cultivation in different countries and require to reform the transportation process, in this study, the effect of frequency and vibration acceleration on mechanical damage of olive have been investigated.

\section{Material and Methods}

\subsection{Sample Preparation}

In this research, olive Mari, a kind of canned olive, was used. Olives were harvested from the Olive Garden of Iranian Research Organization for Science and Technology in early October. Then, separated healthy olives and were kept in a refrigerator at $10^{\circ} \mathrm{C}$ for 24 hours.

\subsection{Physical Properties}

In this research physical, mechanical and Aerodynamic properties of four types of olive named Oily, Fishemi Manzanilla and Kalamata were studied. Samples were obtained from research station of Rudbar ministry agriculture, located in Gilan province. Four trees from each type randomly were selected and almost $1 \mathrm{~kg}$ olive was harvested from different areas of each tree. Then in order to uniformity of olive's moisture, were transferred to laboratory of mechanical properties. After 24hours, samples were taken out from refrigerator and its moisture content was calculated with using standard avon method by putting up 3 repetition from each type at $75^{\circ} \mathrm{C}$ for 24 hours. in this research, the data were analyzed by factorial experiment based on completely random block plan.

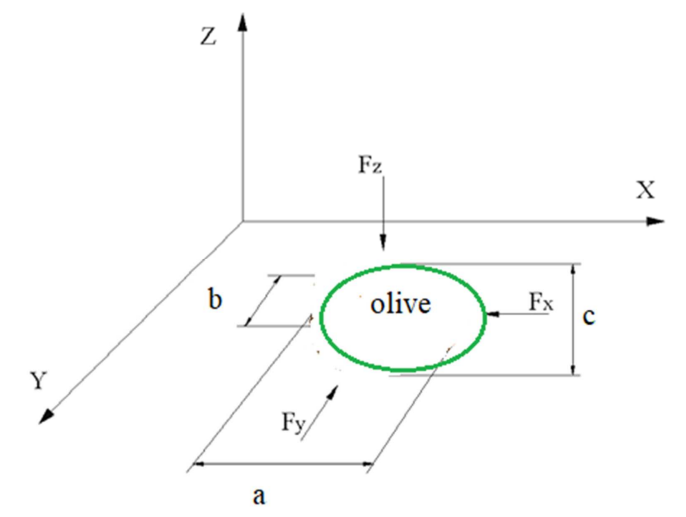

Figure 1. Schematic of the dimensions of the olive fruit.
At first, intact olive from unhealthy olive was separated and to measure fruit dimensions, from every type, 20 olive was selected randomly. Fruit mass and dimension of fruit sequentially with digital scales and digital caliper were measured. Diameter of arithmetic and geometric mean was obtained from formula 1 and 2. generally, the factor used to describe the shape of the fruit is spherical coefficient which was calculated from equation 3 (Mohsenin, 1986). Also, the schematic of the dimensions of the olive fruit is shown in Figure 1.

$$
\begin{gathered}
D_{a}=\frac{a+b+c}{3} \\
D_{g}=(a b c)_{3}^{1} \\
\varnothing=\frac{D_{g}}{a} \times 100
\end{gathered}
$$

According of equation 4, for calculate of volume olive, in order to determination of olive density was used from liquid displacement method. to measure density of olive pile, an empty cylinder was filled with certain volume of olive and then the pile density was obtained by dividing of mass pile on volume pile (equation 5). also, the percentage of porosity pile was obtained by pile density and solid density (equation 6) $[18]$.

$$
\begin{gathered}
p_{t}=\frac{m_{t}}{v_{t}} \\
p_{b}=\frac{m_{b}}{v_{b}} \\
\varepsilon=\left(1-\frac{p_{b}}{p_{t}}\right) \times 100
\end{gathered}
$$

The olive stand friction angle was measured on three different friction surfaces including galvanized sheet, aluminum sheet and steel plate. The product mass is placed in a cylindrical container and placed on the surface. Then cylinder that contain olive is slightly elevated so that its edges do not touch the ramp, and only the samples are in contact with the friction surface to be desired. The angle of slope surface increases gradually with the screw mechanism of the machine and as soon as commence of the slide of the olive sample container, the slope of the device was measured with a accuracy of one degree and The coefficient of static friction angle was calculated using equation 7 .

$$
M_{S=\tan (\alpha)}
$$

\subsection{Mechanical and Aerodynamic Properties}

In order to measure, evaluate and determine the dynamic behavior of olive samples was used the Santam SMT-20 test material and Load Cell $500 \mathrm{~N}$ in a single axial compressive test. The purpose of the single-axial pressure test is to draw force-deformation curves of olive between two plates at $8 \mathrm{~mm}$ / min [19]. The device consists of three main parts: fixed jaw, moving jaw and screen.. In each experiment, according to the force-deformation diagram, the break point was determined and rupture force of the samples was read. Also, the energy 
consumed for breaking the olive sample is obtained by calculating the surface under the force-deformation curve, and by dividing the amount of fracture energy into the sample volume, the amount of Specific deformation was calculated.

\subsection{Vibrating Table}

The vibrating table of the device on which the fruit packs are placed to vibrate include a metal plate with dimensions of $90 \times 150 \mathrm{~cm}$, a moving chassis and a fixed chassis. The moving chassis includes a power transmission system and an outboard system as well as an electromotor, and the plate is connected to it from the top by a screw. The fixed chassis is the location of the springs. The power transmission system consists of two rotary axes each with a threaded arm and outlets centered on these arms, four of which are connected by belt. In two axes, the rotating axes are fitted with similar sized poles that can be rotated with equal but opposite directions for the axes, and four bearings that provide support for the axes. The monetary diameter of each axle is $56 \mathrm{~mm}$, the diameter is $36 \mathrm{~mm}$ and the diameter of the engine head is $28 \mathrm{~mm}$ (Figure 2).

The suspension system consists of eight spiral springs, four of which are movable under the chassis and four on top of it. The springs are located inside the guide bars, which prevent the bars from buckling the springs and preventing them from moving around. As a result, non-vertical movements are prevented. The amount of compression of the springs is adjustable by the vertices that are embedded on their free sides.

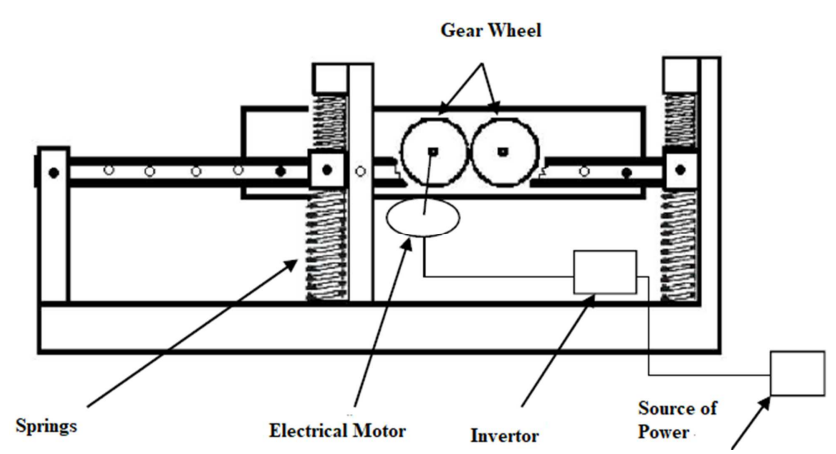

Figure 2. Schematic of Vibration simulator.

\section{Results and Discussion}

\subsection{Physical Properties}

Table 1 shows the mean and standard deviation of the physical properties of the olive samples. According to the apparent factors, it can be claimed that olive samples are classified as spherical fruits in the categories. Also due to the harvest season of olive fruit, which is ripe for fruits, its moisture content is considerable and is approximately $54.36 \%$. It should be noted that the mass of olive fruit has a direct relation with its moisture content, and due to high moisture, the average mass of samples was 3.21 grams.
Table 1. Average and Standard Deviation (SD) of Olive samples.

\begin{tabular}{ll}
\hline property & Canned \\
\hline Length $(\mathrm{mm})$ & $18.45 \pm 1.2$ \\
width $(\mathrm{mm})$ & $18.02 \pm 0.9$ \\
thickness $(\mathrm{mm})$ & $15.32 \pm 1.56$ \\
arithmetic mean diameter $(\mathrm{mm})$ & $14.23 \pm 1.23$ \\
Geometric mean diameter $(\mathrm{mm})$ & $16.11 \pm 1.41$ \\
volume $(\mathrm{mm} 3)$ & $2.95 \pm 0.6$ \\
mass $(\mathrm{gr})$ & $3.21 \pm 0.4$ \\
Moisture $(\%)$ & $54.36 \pm 4.23$ \\
Sphericity coefficient $(\%)$ & $51.32 \pm 8.69$ \\
density $(\mathrm{kg} / \mathrm{m} 3)$ & $510.47 \pm 59.42$ \\
Porosity $(\%)$ & $41.23 \pm 7.69$ \\
area $\left(\mathrm{cm}^{2}\right)$ & $9.75 \pm 1.85$ \\
\hline
\end{tabular}

\subsection{Mechanical Properties}

The average value of the fracture force was 124.48, with the maximum fracture force of $150.77 \mathrm{~N}$ and the lowest value of $108.03 \mathrm{~N}$. The maximum displacement of the fracture was $9.78 \mathrm{~mm}$ and the lowest value was $6.76 \mathrm{~mm}$ and the average displacement was $8.28 \mathrm{~mm}$. The mean values of fracture stress and fracture strain were 0.621 and 0.01609 , respectively, with the maximum and minimum values of 0.750 and $16.79 \mathrm{MPa}$, respectively. The highest modulus of elasticity was $3.558 \mathrm{MPa}$ and the minimum is $2.392 \mathrm{MPa}$ with an average value of $3.09 \mathrm{MPa}$. Based on the results, the mean value of the fracture energy was $515 / 482 \mathrm{~mJ}$ and the maximum and minimum value were 660.36 and $365.34 \mathrm{~mJ}$, respectively.

Table 2. Average and Standard Deviation (SD) of Mechanical Properties.

\begin{tabular}{llll}
\hline \multicolumn{4}{l}{ Mechanical properties } \\
\hline Parameters & $\begin{array}{l}\text { Fracture Force } \\
(\mathbf{N})\end{array}$ & $\begin{array}{l}\text { Fracture Energy } \\
(\mathbf{J})\end{array}$ & $\begin{array}{l}\text { Elastic Module } \\
(\mathbf{M P a})\end{array}$ \\
\hline & SD \pm Average & SD \pm Average & SD \pm Average \\
\hline $\mathrm{F}_{0}$ & $124.84 \pm 10.5^{\mathrm{a}}$ & $515.48 \pm 66.2^{\mathrm{a}}$ & $3.2 \pm 0.9^{\mathrm{a}}$ \\
$\mathrm{F}_{1}=7.5 \mathrm{~Hz}$ & $110.28 \pm 4.22^{\mathrm{b}}$ & $458.96 \pm 12.32^{\mathrm{b}}$ & $2.37 \pm 1.2^{\mathrm{b}}$ \\
$\mathrm{F}_{2}=13 \mathrm{~Hz}$ & $101.88 \pm 5.23^{\mathrm{c}}$ & $450.65 \pm 15.78^{\mathrm{b}}$ & $2.02 \pm 0.18^{\mathrm{c}}$ \\
$\mathrm{A}_{0}$ & $124.84 \pm 10.52^{\mathrm{a}}$ & $515.48 \pm 66.29^{\mathrm{a}}$ & $3.02 \pm 0.29^{\mathrm{a}}$ \\
$\mathrm{A}_{1}=0.3 \mathrm{~g}$ & $108.08 \pm 2.81^{\mathrm{b}}$ & $471.49 \pm 9.36^{\mathrm{b}}$ & $2.39 \pm 0.16^{\mathrm{b}}$ \\
$\mathrm{A}_{2}=0.7 \mathrm{~g}$ & $104.16 \pm 2.81^{\mathrm{c}}$ & $438.12 \pm 7.6^{\mathrm{b}}$ & $2.01 \pm 0.4^{\mathrm{c}}$ \\
$\mathrm{T}_{0}$ & $124.84 \pm 10.52^{\mathrm{a}}$ & $515.48 \pm 66.29^{\mathrm{a}}$ & $3.02 \pm 0.29^{\mathrm{a}}$ \\
$\mathrm{T}_{1}=30 \mathrm{~s}$ & $106.51 \pm 0.83^{\mathrm{b}}$ & $457.29 \pm 10.23^{\mathrm{b}}$ & $2.23 \pm 0.6^{\mathrm{b}}$ \\
$\mathrm{T}_{2}=60 \mathrm{~s}$ & $105.65 \pm 1.56^{\mathrm{c}}$ & $452.3 \pm 13.1^{\mathrm{b}}$ & $2.15 \pm 0.23^{\mathrm{c}}$ \\
\hline
\end{tabular}

According to table 2, using the road vibration simulator, the average effect of the main vibration parameters on mechanical properties measured after vibration with the mechanical properties of the control treatment (before vibration) was performed by independent comparisons. According to the table data, there is a significant difference between the measured properties before vibration (control treatment) and the measured properties after vibration. According to the table, vibrations have reduced properties such as breaking force, failure energy and elastic modulus. For example, variations in the application of the frequency of $7.5 \mathrm{~Hz} / \mathrm{Hz}$ and $13 \mathrm{~Hz}$ in relation to the failure energy are noted, with a reduction of $10.96 \%$ and $12.56 \%$, respectively. Also, the modulus of modulus of elasticity at $7.5 \mathrm{~Hz}$ and 13 $\mathrm{Hz}$ was $21.22 \%$ and $33.11 \%$, respectively. According to the 
table, all factors have a significant effect on these properties. Regarding the changes observed in vibrational factors, it can be said that fatigue in olive fruit has reduced mechanical properties.

Amirian et al. (2013) compared the mechanical properties of calyx cvsmari variety under different pressure loads. Properties including fracture force, fracture energy, failure stress, deflection strain, Young's modulus, toughness and hardness were determined for the calyx of Semsouri. They concluded that the values of mechanical properties before vibration with mechanical properties after vibration (by road vibration simulator) were significantly different. Also, in a study by Georgy et al. (2010), the mechanical properties of two cultivars of apple [20] were compared under compressive stress. Properties including fracture force, failure energy, breaking stress, deflection strain, Young's modulus, toughness and toughness were determined for apples of Golab Kohenz and Shafi Abadi. They concluded that the values of mechanical properties for Shafi Abadi cultivar were greater than that of Kohnz [21].

\section{Conclusion}

Olive is one of the strategic fruits in the world especially in Iran. All agricultural products have certain specifications and factors. Mechanical properties including fracture force, breaking stress, failure displacement, failure strain, failure energy, elastic modulus, toughness and hardness can be used to study damage to products such as the transfer of seeds, fruits, vegetables and some foods Used them. In this research, after simulating vibrations on olive samples, there were visual injuries in the surface of the product in the product and no other mechanical injuries including fractures or fractures were observed in the product. This suggests that vibrations in the olive fruit cause the appearance of damage in the form of a bruise, which itself could be due to the exacerbation of the impact and wear by vibrations. According to comparisons done before and after vibration on frequency, it was observed that the effect of frequency on mechanical properties was significant. Therefore, it is better to use vehicles for less damage and less damage to the products, with a vibrational frequency of $7.5 \mathrm{~Hz}$. The highest level of damage to the product was due to the combination of the frequency $13 \mathrm{~Hz}$, acceleration $0.7 \mathrm{~g}$, third level (high) and time of 60 minutes. Also, the least damage to pomegranate fruit is due to the combination of a frequency of $7.5 \mathrm{~Hz}$, acceleration of $0.3 \mathrm{~g}$, first level (lower) and time of 30 minutes.

\section{Acknowledgements}

The authors would like to Machine design and Mechatronics Department, Institute of Mechanics, Iranian Research Organization for Science and Technology for their contributions to this study.

\section{References}

[1] Barbera, A. C., Maucieri, C., Cavallaro, V., Ioppolo, A., \& Spagna, G. (2013). Effects of spreading olive mill wastewater on soil properties and crops, a review. Agricultural Water Management, 119, 43-53.

[2] Lupi, F. R., Gabriele, D., Facciolo, D., Baldino, N., Seta, L., \& De Cindio, B. (2012). Effect of organogelator and fat source on rheological properties of olive oil-based organogels. Food Research International, 46 (1), 177-184.

[3] Rigacci, S., \& Stefani, M. (2016). Nutraceutical properties of olive oil polyphenols. An itinerary from cultured cells through animal models to humans. International journal of molecular sciences, 17 (6), 843 .

[4] Özcan, M. M., \& Matthäus, B. (2017). A review: benefit and bioactive properties of olive (Olea europaea L.) leaves. European Food Research and Technology, 243 (1), 89-99.

[5] Wei, J., Junle, L., Jun, Y., Shihong, D., \& Dean, Z. (2015). Analysis and validation for mechanical damage of apple by gripper in harvesting robot based on finite element method. Transactions of the Chinese Society of Agricultural Engineering, 31 (5).

[6] Opara, U. L., \& Fadiji, T. (2018). Compression damage susceptibility of apple fruit packed inside ventilated corrugated paperboard package. Scientia horticulturae, 227, 154-161.

[7] Zhang, Z., Heinemann, P. H., Liu, J., Baugher, T. A., \& Schupp, J. R. (2016). The development of mechanical apple harvesting technology: A review. Transactions of the ASABE, 59 (5), 1165-1180.

[8] Li, Z., \& Thomas, C. (2014). Quantitative evaluation of mechanical damage to fresh fruits. Trends in Food Science \& Technology, 35 (2), 138-150.

[9] Castro-Garcia, S., Rosa, U. A., Gliever, C. J., Smith, D., Burns, J. K., Krueger, W. H., ... \& Glozer, K. (2009). Video evaluation of table olive damage during harvest with a canopy shaker. HortTechnology, 19 (2), 260-266.

[10] Abedi, M., and E. Ahmadi. 2014. Bruise susceptibilities of Golden Delicious apples as affected by mechanical impact and fruit properties. The Journal of Agricultural Science 152 (3): 439-447.

[11] Schulte N. L., E. J. Timm, and G. K. Brown. 1994. 'Redhaven' peach impact damage thresholds. Horticulture Science 29 (9): 1052-1055.

[12] Milczarek, R. R., Saltveit, M. E., Garvey, T. C., \& McCarthy, M. J. (2009). Assessment of tomato pericarp mechanical damage using multivariate analysis of magnetic resonance images. Postharvest Biology and Technology, 52 (2), 189-195.

[13] Afshari, H., S. Minaeei, M. Almasi, and P. Abdolmaleki. 2006. The assessment of potato damage under dynamic loading. Journal of science and food industry 5 (2): 69-79.

[14] Mohammad Shafie, M. A. Rajabipour, H. Mobli, and M. Khanali. 2016. The effect of dropping impact on bruising pomegranate fruit. Journal of Agricultural Machinery 6 (1): 176-187. 
[15] Reisiestabrahg, A. (2015). The effect of vibrations simulated on tomatoes. First National Conference on the Environment \& Food Security, University of Jiroft.

[16] Ranathunga, C. L., Jayaweera, H. H. E., Suraweera, S. K. K., Wattage, S. C., Ruvinda, K. K. D. \& Ariyaratne, T. R. (2010). Vibration effects in vehicular road transportation. Institute of Physics - Sri Lanka Proceedings of the Technical Sessions, 26, 9-16.

[17] Zhou, R., Su, S., Yan, L. \& Li, Y. (2007). Effect of transport vibration levels on mechanical damage \& physiological responses of Huanghua pears. Postharvest Biology \& Technology, 46 (1), 20-28.

[18] Shahbazi, F., Rajabipour, A., Mohtasebi, S. \& Rafie, Sh.
(2008). Effects of transport vibrations on modulus of elasticity watermelon, variety crimson sweet. Iranian Journal of Biosystem Engineering, 40 (1), 15-25.

[19] Mohsenin, N. N., 1986. Physical Properties of Plant and Animal Materials. 2nd, Edn., Gordon and Breach Science Publishers, New York, N. Y.

[20] Tavakoli, M., Tavakoli, H., Azizi, M. H., \& Haghayegh, G. H. (2010). Comparison of mechanical properties between two varieties of rice straw. Advance Journal of Food Science and Technology, 2 (1), 50-54.

[21] Vursavuş, K., \& Özgüven, F. (2004). Mechanical behaviour of apricot pit under compression loading. Journal of Food Engineering, 65 (2), 255-261. 